\title{
The Recovery of the Historic Centres in the Metropolitan Area of Reggio Calabria through the Use of Bergamot
}

\author{
Daniele Campolo ${ }^{1, a}$ \\ 1“"Mediterranea” University of Reggio Calabria - P.A.U. - Department of Heritage, Architecture, Urban \\ Planning, via Salita Melissari - 89124, Reggio di Calabria, Italy \\ adaniele.campolo@unirc.it
}

\begin{abstract}
Keywords: Bergamotto, Recovery, Historic Buildings, Environmental Degradation, Production Waste, Land Degradation, Soil Consumption
\end{abstract}

\begin{abstract}
The abuse of land is devastating our country: environmental disasters (landslides, floods, mudslides, etc.) are becoming more frequent because of the abandonment of agricultural lands and an inadequate care of the land, particularly in the inland areas.

But Calabria, and the province of Reggio Calabria, in particular, has agricultural vocations that makes it unique in the Italian panorama and there could be development opportunities for the region, not only in the agriculture sector but also in the recovery of the historic centers with an innovative use of waste materials coming from the production of bergamot, or citrus, for the restoration of historic buildings and vernacular architecture.

From a metropolitan city point of view, we must put an end to the soil consumption in favor of the recovery and the enhancement of endogenous resources, utilizing innovative techniques and innovative methods we can diversify the use of existing resources to make them more productive.
\end{abstract}

\section{Introduction}

In the last decades the alarms for land degradation, because of the abandonment of the agricultural lands, with the destruction of the landscape and the waste of natural resources is worrying the entire scientific community.

In February 2013 some researches of I.S.P.R.A (Institute for the Environmental Protection and Research) have shown the frenetic rate of the soil consumption: $8 \mathrm{~m}^{2}$ per second in the last five years; we have passed from a consumption of $8,000 \mathrm{Km}^{2}$ in 1956 to a consumption of over $20,500 \mathrm{~km}^{2}$ in 2010, while in Europe the average consumption is $2.8 \%$, in Italy it overtakes $6.9 \%$ [1].

The covering of the soil surface with impervious materials as a result of urban development and infrastructure construction is known as soil sealing. This phenomenon causes irreparable damages to agriculture and decreases the utilized agricultural area. Sealed areas are lost to uses such as agriculture or forestry while some ecological soil functions are severely impaired or even prevented: primary production function, regulation of water, conservation of biodiversity, etc.

In the metropolitan area of Reggio Calabria, linked to the failed process of Calabria's industrialization ("Liquichimica" and "Officine Grandi Riparazioni" of F.S. in Saline Ioniche) we need to invest in the agri-food sector, because it allows to enhance and revitalize agriculture, environment and tourism. We should aim primarily for those agricultural products that could become leaders: olives, citrus fruits, but also the milk sector that is disappearing now but had a strong tradition in Calabria in the past times.

In particular, the citrus industry has a resource, which makes the metropolitan area of Reggio Calabria, unique in the world, with an enormous potential for development and technological innovation: the bergamot. 


\section{The bergamot}

Bergamot - Citrus bergamia, Risso - is a citrus fruit of unknown origins: bergamot has been present in Calabria since the end of the 14th or beginning of the 15th century and the first bergamot plantation in Calabria was established in 1750. Later the new type of cultivation became rapidly wide-spread.

The cultivation of this citrus fruit is closely related to the "Acqua admirabilis", a toilet water: the essential oil of bergamot is the basic component of the "Eau de Cologne" and of other perfumery products.

The bergamot tree is a very strong plant because it is produced by grafting onto a bitter orange, that makes it resistant and durable.

The world production is mostly concentrated in Italy (at least 90\%), and it's and exclusivity of the province of Reggio Calabria: the bergamot is cultivated along the Ionian coast of this Province, specifically between the towns of Villa San Giovanni and Gioiosa Jonica; an area of about 1,500 hectares produces 200,000-250,000 quintals of this fruit, which yields an average of 100,000 $\mathrm{kg}$ of essence, then with a yield of $0.5 \%$.

The ISTAT data on citrus production in Calabria (2006-2012), confirmed by those provided by the Consortium of Bergamot and by on field investigations, highlights how the production of bergamot in recent years has remained almost constant with an increase only in the recent years (Table 1).

The plants of bergamot in the province of Reggio Calabria are characterized by a high yield and a good quality of the essential oil.

The harvest of the fruit, generally between April and May, must be carried by hand to avoid damages to the "utricles" containing the essence with high production costs (about 15-20 euro per kg of fruit).

\begin{tabular}{|l|l|l|l|l|}
\hline \multicolumn{5}{|c|}{ Table 1: Production of bergamot in the province of Reggio Calabria } \\
\hline $\begin{array}{l}\text { year of area } \\
\text { production }\end{array}$ & $\begin{array}{l}\text { total area } \\
{[\text { ha] }}\end{array}$ & $\begin{array}{l}\text { production } \\
{[\text { ha }]} \\
{[\text { quintals }]}\end{array}$ & $\begin{array}{l}\text { harvested } \\
\text { production } \\
\text { quintals }]\end{array}$ \\
\hline 2012 & 1800 & 1800 & 423000 & 401850 \\
\hline 2011 & - & - & - & - \\
\hline 2010 & 1461 & 1439 & 254736 & 254736 \\
\hline 2009 & 1461 & 1449 & 248552 & 248552 \\
\hline 2008 & 1461 & 1424 & 255161 & 255161 \\
\hline 2007 & 1461 & 1461 & 140256 & 140256 \\
\hline 2006 & 1461 & 1461 & 350240 & 350240 \\
\hline
\end{tabular}

The data related to the production waste are equally important: about 50\% (10,000 tons) in the amount of produced fruit becomes waste material, named "pastazzo" (squeezed peel and pulp waste from the processing of the citrus fruits). The "pastazzo" is partly reused as feed for animals, in a market very unstable and not very profitable, and in part is transferred to landfills with additional costs of disposal.

\section{Technological innovation and traditional technologies}

Just the waste production of bergamot, thanks to the organoleptic and antiseptic characteristics, could be used in productive and innovative ways in the recovery of historic buildings, creating materials and building technologies that are inspired to the building tradition of the "Grecanic Area".

This alternative use of waste production could also be extended to wastes derived from pruning or other citrus productions. In particular the orange waste cannot be easily used in different ways.

The settlements of the "Grecanic Area", characterized by scarcity of resources, are made with buildings materials and technologies readily available in the surrounding areas. 
The recovery materials strongly characterize the local building techniques in the pursuit of the most recent rules of sustainable architecture: plasters and mortars were made of sand and lime coming from the surrounding territories; the walls were built with little stones recovered in the characteristic Calabrian rivers; the interior partitions as well as ceilings, were made with a "framed" wooden structure of intertwined branches, small axes or intertwined canes (known as "cannizzi") covered with lime mortar; all paints were made with slaked lime.

Just in this research field, some experiments have already been carried out with the realization of a plaster with waste material of bergamot: the oral tradition of the area tell us that this material was commonly used in poor areas with little resources, even in the absence of material evidence or documents [2].

In addition to the creation of plaster mixed with bergamot it is also possible to create painting with "slaked lime from the limestone of Palizzi added with the pulp of bergamot, finely crushed and sieved from fibrous residue inclusions" (Fig. 1-2) [2].
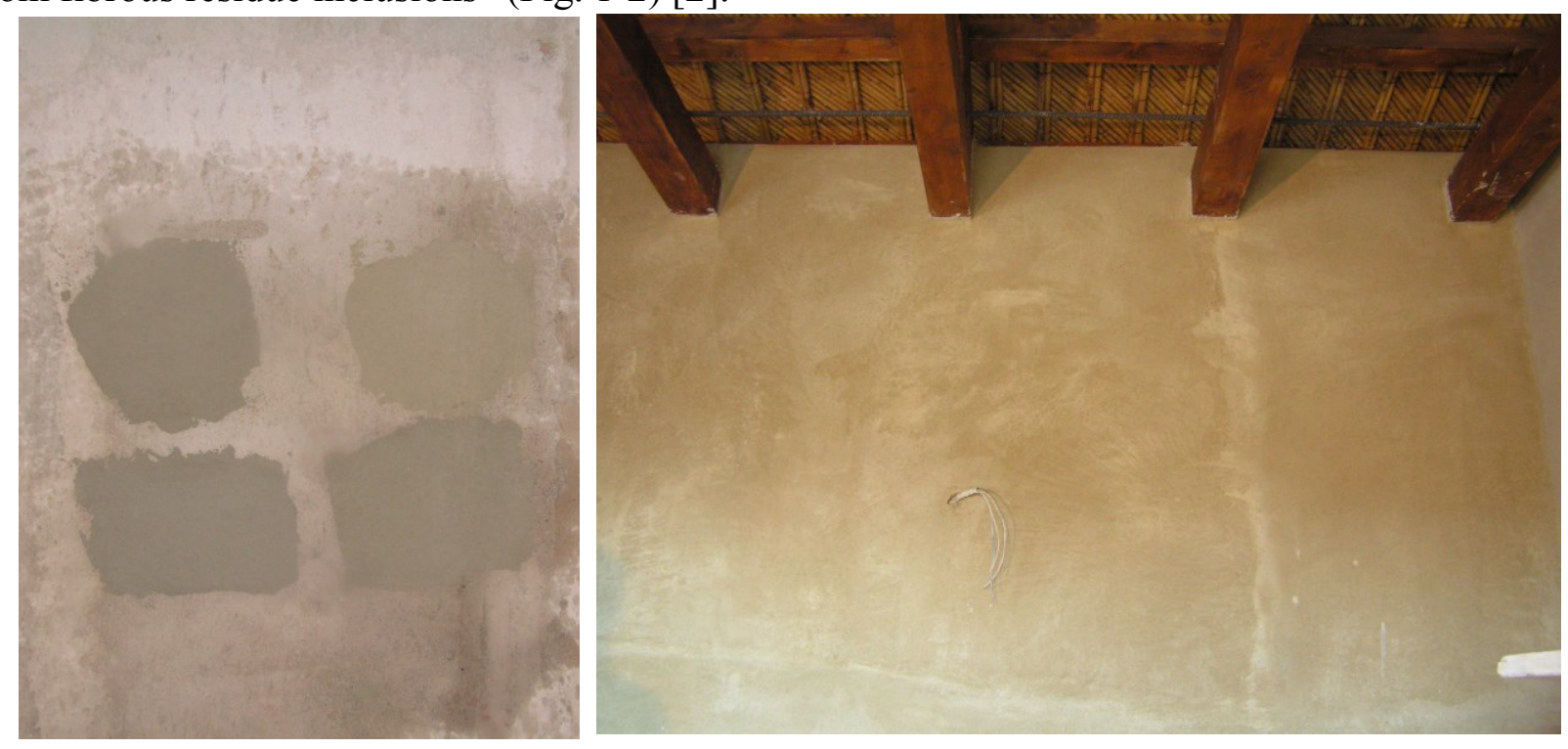

Fig.1-2: Plaster additived with bergamot (A. Bianco)

Some different studies have been carried out in a experimental site in the Grecanic Area: the research, carried out by the University Mediterranea of Reggio Calabria, shows promising results and worthy of further experimentations because of the antibacterial properties of the bergamot's "pastazzo" [3].

Starting from the experiments carried out and the existing technologies, and still easily recognizable in the territory, "alternative" and innovative uses of the waste production of bergamot might be identified. The realization of new combinations in building materials, using not only the bergamot waste but citrus in general, can achieve the aims of: enhancing the features of bergamot diversifying the use of the products in different economic sectors; improving a more sustainable use of resources and building projects; developing a recovery of vernacular architecture with materials compatible with the historic character.

The bergamot is characterized by its multiple uses and for the many beneficial properties that favor its use in many fields and industries, some of them have been proved over a long period of time: it is the fundamental ingredient not only in the traditional Eau-de-Cologne but also in numerous other delicate perfumery products, cosmetics, pharmaceutical industry and food industry.

The development of a process for implementing the multi-functionality of this product may relate to the solution on the disposal of waste products, which are generally destined for landfill, or the production of livestock feed.

In particular the "pastazzo", (hundreds of tons every year), with field research in historical centers, could be re-used, with a greater market value, as an additive of plaster, of painting or just, once dried, 
as insulating material for partitions. We can find a lot of these examples in the historical centers of the "Grecanic Area" where the "spontaneous" architecture, in the past centuries, was rich in this knowledge.

The essential oil of bergamot could also be used for the impregnation of wood used for the recovery, and as an additive for painting based on lime: in fact in addition to the already known antibacterial properties, bergamot contains within it terpenes. Terpenes are a large and diverse class of organic compounds, with a protective function, could be used also as a solvent for paints in the recovery of historic buildings or vernacular architecture [4].

\section{Conclusions}

The bergamot's heritage has a considerable importance in the socio-economic reality of the province of Reggio Calabria, but the market of the essential oil of bergamot, since the beginning of this century, has been subject to strong speculative pressures for the fluctuations in production and prices. These factors have led to recurring crises in this sector, exacerbated by instrumental campaigns of the multinational manufacturer industries of synthetic essences.

The cultivation and production of bergamot has become a development opportunity for the rural areas of the province of Reggio Calabria where this citrus fruit is produced: the promotion of its culture, the sustainable use of all its products, including wastes, can become a catalyzing element for economic and sustainable development through an integrated project for the enhancement of the production of bergamot; the recovery and reuse of these abandoned historic centers in the province of Reggio Calabria, which represent the genius loci of the "Grecanic Area" and that are historically the place of production of the "citrus bergamia" [5].

The typical characteristics of the territory and the exclusivity of the product can create a synergy between sustainable agriculture, territorial balance, landscape conservation and restoration of historical centers: they can strengthen the identity and the unique elements of the area and they can promote a "sustainable" development that starts from the promotion and enhancement of productive economic system.

In conclusion the prospects of promotion and enhancement of this citrus fruit and its derivatives, exclusive of the province of Reggio Calabria, in its multiple functions and features, could bring added value to companies and could constitute, in the future, the economic and productive improvement of the "whole chain" of bergamot, providing concrete opportunities for further development for the entire metropolitan area.

\section{References}

[1] S. Settis: Lectio Magistralis “L'etica dell'architetto ed il restauro del paesaggio” Reggio Calabria 14 gennaio 2014

[2] A. Bianco: Prime sperimentazione di malte di calce di Palizzi additivate: il cantiere test di Bova M. in "LaborEst", anno 2009 n.3, p. 101-108

[3] M. Ambrogio, A. Bianco, N. Porpiglia: L'intonaco con calce di Palizzi additivita al bergamotto: analisi batteriologiche, in "LaborEst", anno 2009 n. 4, p. 86-89

[4] L. Mondello, A. Verzera, P. Previti, F. Crispo, G. Dugo: Multidimensional Capillary GC-GC for the Analysis of Complex Samples. 5. Enantiomeric Distribution of Monoterpene Hydrocarbons, Monoterpene Alcohols, and Linalyl Acetate of Bergamot (Citrus bergamia Risso et Poiteau) Oils, in: J. Agric. Food Chem., pp. 4275-4282, (1998), DOI: 10.1021/jf980228u

[5] F. Calabrò, L. Della Spina: The public-private partnerships in buildings regeneration: a model appraisal of the benefits and for land value capture. In: 5nd KKU International Engineering Conference 2014 (KKU-IENC 2014). ADVANCED MATERIALS RESEARCH, Vols. 931-932 (2014) pp 555-559 (C) (2014) Trans Tech Publications, Switzerland doi:10.4028/www.scientific.net/AMR.931-932.555, (2014) 